European Association for the Development of Renewable Energies, Environment and Power Quality
International Conference on Renewable Energies and Power Quality (ICREPQ’09)

Valencia (Spain), 15th to 17th April, 2009

\title{
Eucalyptus globulus waste as fuel in a power plant
}

\author{
S. Pérez, C. J. Renedo, A. Ortiz, M. Mañana, C. Tejedor, N. Sanke, F. Delgado \\ Deparment of Electrical and Energy Engineering, University of Cantabria \\ Av Los Castros s/n 39005 Santander Cantabria \\ Teléfono: 9422013 82, Fax: 942201385 \\ e-mail: perezrs@unican.es
}

\begin{abstract}
This paper analyzes the energy potential which waste from the forestry eucalyptus globulus in Cantabria, with particular reference to their potential for direct combustion in power plants. This has made a software in which introducing the values for the various parameters that affect combustion, provides results in flame temperature and electrical performance.
\end{abstract}

\section{Key words}

Biomass, eucalyptus globulus, combustion, flame temperature, performance

\section{Introduction}

The summit held in Kyoto in December 1997 signed the famous Kyoto protocol, which will adopt a series of measures aimed at reducing emissions of greenhouse gases by 39 industrialized countries including Spain. The commitment requires to limit emissions of six gases including $\mathrm{CO} 2, \mathrm{CH} 4, \mathrm{~N} 2 \mathrm{O}$, CFC, HFC and SF6, for the first three gases reductions were set in the 1990-95 period, and for three seconds in the $2008 / 12$ period.

In the case of the European Union, this reduction should be an eight per cent. To achieve this, it is essential to the empowerment and development of renewable energy, figure 1.

Subsequently, at the European Conference for Renewable Energies held in Berlin in 2004,

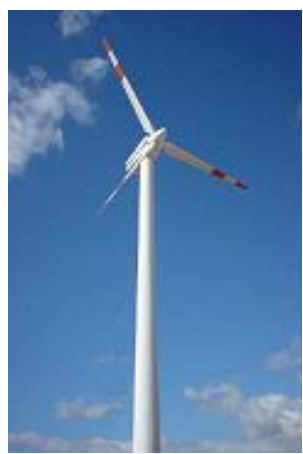

a) wind

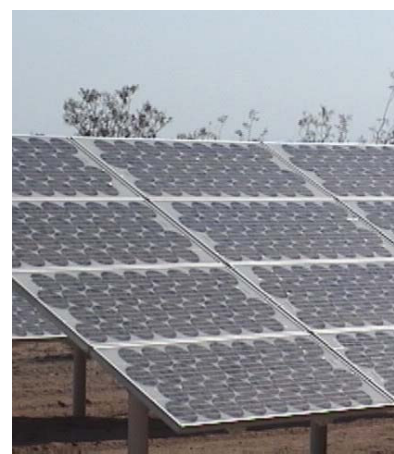

b) solar attended by 650 participants from 45 countries discussed the situation of renewable energy in Europe, including evaluating projects and policies implemented both at EU level, as national and local levels.

All this leads, with the aim of achieving sustainable development, to investigate and implement initiatives that drive to harness those resources of renewable energy which are available in enough abundance in each region.

One of the most important renewable energy sources, from the point of view of quantity, in the north coast of Spain, is the biomass of forest origin. In this case, the waste left on the mountain after the conventional exploitation of wood.

This paper analyzes thermodynamically for the autonomous community of Cantabria, peculiarities that have forest residues as fuel in use in a thermal power station.

This study is warranted in Cantabria that $15 \%$ of forest area is designed to fast-growing species, particularly eucalyptus globulus (EG) [1]. This area of 35,000 hectares, representing $24 \%$ of timber production, reason enough to consider the EG as the true protagonist in this region [2].

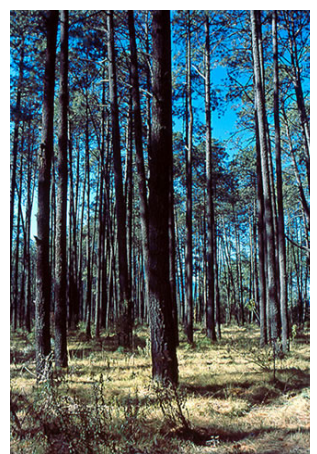

c) biomass

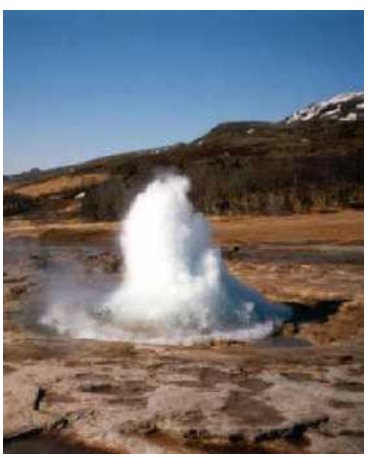

d) geothermal
Figure 1. Typical sources of renewable energy 
According to official figures, 523,000 cubic meters of EG are cut annually in Cantabria [3], figure 2, taking an average density of the wood from 750 $\mathrm{kg} / \mathrm{m} 3$ and taking into account that $20 \%$ of the total weight of a tree of species under study are waste [4], about 105,000 tons of waste of this species are produced annually.

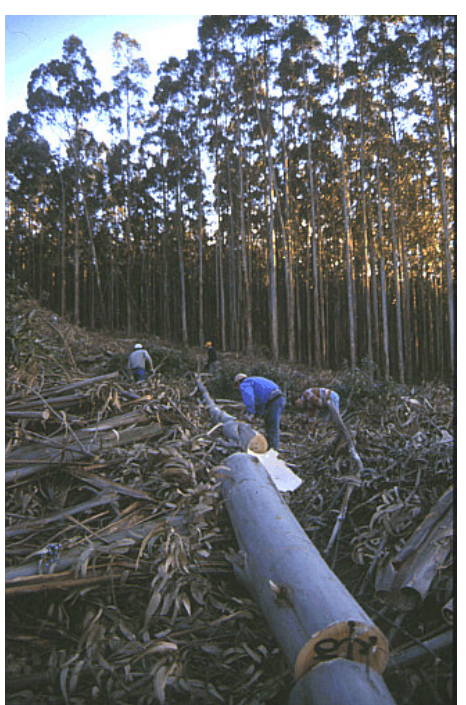

Figure 2. EG forest residues.

\section{Biomass as fuel}

Fuel is any substance that reacts with oxygen (combustion) is oxidized giving off heat, but actually fuels are considered only those substances that release enough heat to be exploited.

The use of thermal fuel usually takes place in a boiler, which is a device that takes place in the process of combustion and heat over a heat fluid flowing through it, in the case of heating a liquid, this could suffer a vaporization.

The calorific value is the amount of heat per unit of mass which produce a fuel when is burned; two calorific values are defined:

1. Net calorific value (NCV), which is the heat that produces the fuel when the water vapour content in the smoke is not condensed, is the one normally used.

2. Gross calorific value (GCV), which is what appears in the combustion when the water vapour in the smoke is collected condensated; is greater than or equal to the $\mathrm{NCV}$, as it harnesses the latent heat of condensation of the water contained in the smoke.

Logically, the difference between PCI and PCS is greater the higher the hydrogen content of fuel, and the higher the moisture content of both the oxidizer and fuel in particular, usually high value on biomass. In Table 1 [2, 3, 4] shows the calorific value of some fuel.

The basic elements that act as fuel are carbon and hydrogen [5], which are part of the chemical composition of fuel, which also often contain elements or other impurities that can also oxidize (such as sulfur) or remain inert (ash ).

The reactions that have carbon in combustion are:

$$
\begin{gathered}
\mathrm{C}+\mathrm{O} 2=\mathrm{CO} 2+32.780 \mathrm{~kJ} / \mathrm{kg} \\
\mathrm{C}+1 / 2 \mathrm{O} 2=\mathrm{CO}+9.188 \mathrm{~kJ} / \mathrm{kg} \\
\mathrm{CO}+1 / 2 \mathrm{O} 2=\mathrm{CO} 2+10.111 \mathrm{~kJ} / \mathrm{kg}
\end{gathered}
$$

The reaction of hydrogen combustion is:

$$
\mathrm{H} 2+1 / 2 \mathrm{O} 2=\mathrm{H} 2 \mathrm{O}+118,680 \mathrm{~kJ} / \mathrm{kg}
$$

If the condensed water is collected and not in the form of vapor, the heat reaches the value of $142,107 \mathrm{~kJ} / \mathrm{kg}$. But usually the boilers are not prepared to support the condensation of water vapor content in the smoke, it is because of this that the surface temperature of the boiler that may come into contact with smoke, you must have a temperature above the point dew-wet smoke, this value depends on the composition of fuel and the excess air with which he has conducted combustion.

Although biomass does not contain sulfur in its composition, for being present in the fuel, the reaction is:

$$
\mathrm{S}+\mathrm{O} 2=\mathrm{SO} 2+2,957 \mathrm{~kJ} / \mathrm{kg}
$$

Produced SO2 reacts easily with water vapor produced during combustion, leading to the formation of sulfuric acid by the following reaction:

$$
\mathrm{SO}_{3}+\mathrm{H}_{2} \mathrm{O}=\mathrm{SO}_{4} \mathrm{H}_{2}
$$

This is why there is an acid dew point, which is very important for fuels with more than $0.7 \%$ sulfur content, since the occurrence of the sulfuric acid corrosion of metal surfaces in very quickly.

Regarding the oxidizer, it is known that to produce the complete combustion of all fuel, meaning that all carbon in the fuel reaches oxidize as $\mathrm{CO}_{2}$, which are present or without $\mathrm{CO}$ or $\mathrm{O}_{2}$ in smoke, the reaction should be produced stoichiometric, should adjust the amount of oxidizer to the fuel used, which implies that: 
Table 1. Calorific value of some fuel

\begin{tabular}{|l|r|r|r|r|}
\hline \multirow{2}{*}{ Fuel } & \multirow{2}{*}{ GCV $(\mathrm{kJ} / \mathrm{kg})$} & \multicolumn{3}{|c|}{ NCV $(\mathrm{kJ} / \mathrm{kg})$} \\
\cline { 3 - 5 } & & Without moisture & $20 \%$ moisture & $40 \%$ moisture \\
\hline Natural Gas & 42,696 & 33,120 & & \\
Propane & 101,916 & 93,672 & & \\
Butane & 134,208 & 123,732 & & \\
\hline Diesel C & 45,290 & 42,343 & & 10,676 \\
\hline Coniferous branches & 20,725 & & 15,031 & 9,797 \\
Leafy branches & 19,259 & & 13,858 & 10,509 \\
Coniferous dusts & 20,432 & & 14,821 & 9,839 \\
Indigenous leafy dusts & 19,385 & & 13,733 & 10,509 \\
Lush tropical dusts & 20,390 & & 14,779 & 11,095 \\
Coniferous bark & 21,060 & & 15,282 & 9,965 \\
Leafy bark & 19,552 & & 14,110 & \\
\hline
\end{tabular}

$$
\begin{array}{ll}
\mathrm{C}+\mathrm{O}_{2}=\mathrm{CO}_{2} & 12 \mathrm{~g} \text { of } \mathrm{C} \text { need } 22.4 \mathrm{l} \text { of } \mathrm{O}_{2} \\
\mathrm{H}_{2}+1 / 2 \mathrm{O}_{2}=\mathrm{H}_{2} \mathrm{O} & 2 \mathrm{~g} \text { of } \mathrm{H}_{2} \text { need } 11.21 \text { of } \mathrm{O}_{2} \\
\mathrm{~S}+\mathrm{O}_{2}=\mathrm{SO}_{2} & 32 \mathrm{~g} \text { of } \mathrm{S}_{2} \text { need } 22.4 \text { l of } \mathrm{O}_{2}
\end{array}
$$

Assuming that the oxygen content of atmospheric air is $21 \%$, it takes 4.76 times more air volume of oxygen stoichiometric.

In this way, knowing the fuel composition is possible to see the amount of oxygen, and therefore air for combustion.

Forest biomass is a fuel whose use, when compared with other fuels, such as, for example, petroleum products, has several drawbacks, among them include:

The location, the masses of trees are scattered in nature, occupying large tracts of land, which normally is often difficult terrain, which makes their collection is problematic, and therefore represents a high cost. This problem does not exist in the case of industrial forest biomass.

Moreover, this biomass is a compact little or nothing, so the density is very low and therefore the volume that covers both the transport and storage is high, which makes these processes expensive.

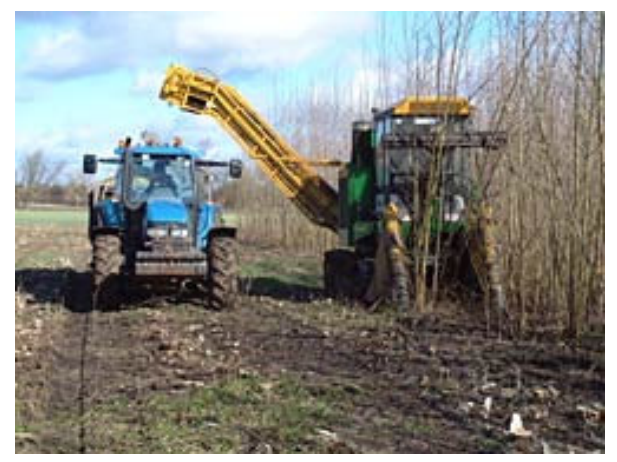

Figure 3. Shredder
To overcome or mitigate these effects, there are machines that collect, crush, figure 3 , or compacted, figure 4 , the waste at source, the election process depends primarily on the topography of the land but, despite lower overall costs, the placing price of waste in the park (point of load in the forest) is high.

Until now, we have discussed the drawbacks of forest biomass energy, but also many advantages of using this energy source, the impact of various kinds, including social, economic, environmental, etc., including are:

- Biomass is an indigenous resource, so its use helps to eliminate the heavy dependence on energy that Spain has with the oil-producing countries, natural gas, etc.

- The use of biomass as an energy source involves the enhancement of existing resources and potential in rural areas traditionally deprived areas which tend to depopulate by shortage of funds for its residents. Studies in Germany, resulting in the biomass energy created between 3.3 and 5 more jobs than the gas, or between 2.8 and 4.3 more than the oil [8].

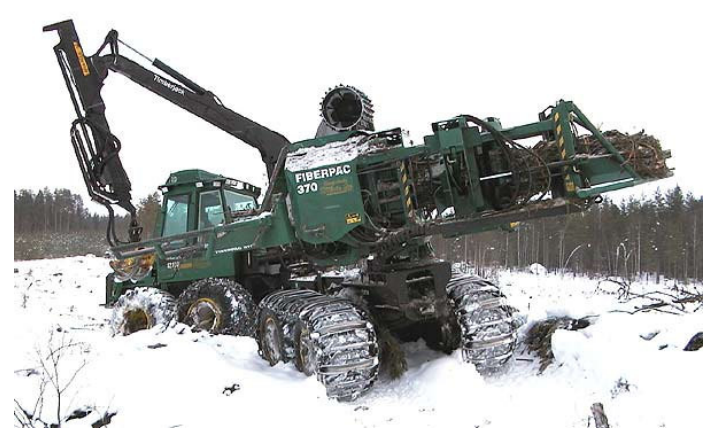

Figura 4. Compaction machine 
- Enhancing energy involves such dedication of land to energy crops, an environmental advantage by helping to mitigate the greenhouse effect, because the masses plants behave as sinks of $\mathrm{CO} 2$.

- From an economic point of view, it can be noted that the Royal Decree 436/2004 [9] sets forest biomass b.6 within the group, which is included in the special scheme to sell electricity at a rate of $90 \%$ of the average rate regulated, which represents an advantage over other energy sources.

It is evident that the performance in electricity production is low compared to other types of fuels (coal, natural gas, ...), but when used with CHP, the overall energy performance will be similar to that achieved by the use of other fuels of higher quality energy. Can be very interesting job in the facilities they need hot water or heating, such as farms, gyms, swimming pools, etc., or as is happening in the Nordic countries, for district heating.

This paper will attempt to analyze the characteristics in terms of thermodynamic their advantages and disadvantages. Assume that the residue is burned in a power, to generate steam in a cycle of power. The study was conducted for the autonomous community of Cantabria and waste are to study the species EG.

To burn waste as any other residue is necessary to know some technical parameters that determine the computer technology for energy. One of these parameters is the adiabatic flame temperature is reached in the combustion.

Depending on the maximum temperature opt for a central or a conventional steam combined cycle power.

To install a combined cycle power necessary flame temperatures close to 1150 degrees centigrade.
To calculate the flame temperature of a fuel [6], it is necessary to consider an energy balance. This requires knowing the chemical composition for forest residues can be seen from cellulose, hemicellulose and lignin [7] and the conditions of combustion, that is with an oxygen fuel mixture is complete, and gases behave like perfect, you get:

$$
\begin{gathered}
\mathrm{E}_{\text {reactivos }}=\mathrm{E}_{\text {productos }} \\
\sum_{\text {reactivos }} \mathrm{n}_{\mathrm{r}}\left(\mathrm{h}_{\mathrm{f}}+\Delta \mathrm{h}_{\mathrm{f}}\right)_{\mathrm{r}}=\sum_{\text {productos }} \mathrm{n}_{\mathrm{p}}\left(\mathrm{h}_{\mathrm{f}}+\Delta \mathrm{h}_{\mathrm{f}}\right)_{\mathrm{p}}
\end{gathered}
$$

being $n_{\mathrm{r}} \quad$ number of moles of reactant

$n_{\mathrm{p}}$ number of moles of product

$h_{\mathrm{f}} \quad$ formation enthalpy

$\Delta h_{\mathrm{f}}$ enthalpy variation

In Table 2 and 3 reflect the properties of forest residues and basic combustion reactions, and its components $[6,8]$, considering the air $21 \%$ oxygen and $79 \%$ nitrogen.

Table 3. Properties of combustion products

\begin{tabular}{|c|c|c|c|}
\cline { 2 - 4 } \multicolumn{1}{c|}{} & $\mathrm{CO}_{2}$ & $\mathrm{H}_{2} \mathrm{O}$ & $\mathrm{N}_{2}$ \\
\hline$h_{\mathrm{f}}(\mathrm{kJ} / \mathrm{kmol})$ & $-393,520$ & $-241,820$ & 0 \\
\hline $\mathrm{c}_{\mathrm{p}}(\mathrm{kJ} / \mathrm{kg} \mathrm{K})$ & 37.11 & 38 & 28.9 \\
\hline
\end{tabular}

Assuming that $100 \mathrm{~kg}$ of reactants fall, ie, 0.234 , 0.0122 and 0.044 kmoles cellulose, hemicellulose and lignin, respectively, the products of combustion are:

$$
\begin{gathered}
0.234 \mathrm{kmol} x\left[6 \mathrm{CO}_{2}+5 \mathrm{H}_{2} \mathrm{O}+(6 x 3.76) \mathrm{N}_{2}\right]+ \\
+0.0122 \mathrm{kmol} x\left[408 \mathrm{CO}_{2}+302 \mathrm{H}_{2} \mathrm{O}+(403 x\right. \\
\left.3.76) \mathrm{~N}_{2}\right] / 4+ \\
+0.044 \mathrm{kmol} \times\left[160 \mathrm{CO}_{2}+82 \mathrm{H}_{2} \mathrm{O}+(181 x 3,76)\right. \\
\left.\mathrm{N}_{2}\right] / 4= \\
=4.404 \mathrm{kmol} \mathrm{CO} \mathrm{CO}_{2}+2.992 \mathrm{kmol} \mathrm{H} \mathrm{O}+17.39 \mathrm{kmol} \\
\mathrm{N}_{2}
\end{gathered}
$$

Table 2. Properties of components of forest residues

\begin{tabular}{|c|c|c|c|}
\hline Composition & Cellulose $(38 \%)$ & Hemicellulose $(32 \%)$ & Lignin (30\%) \\
\hline Chemical formula & $\mathrm{C}_{6} \mathrm{H}_{10} \mathrm{O}_{5}$ & $\mathrm{C}_{102} \mathrm{H}_{151} \mathrm{O}_{78}$ & $\mathrm{C}_{40} \mathrm{H}_{41} \mathrm{O}_{10}$ \\
\hline Molecular Weight & 162 & 2623 & 681 \\
\hline$\Delta \mathrm{hf}(\mathrm{kJ} / \mathrm{kg})$ & $17,455.6$ & 174,556 & 21,178 \\
\hline$\Delta \mathrm{hf}(\mathrm{MJ} / \mathrm{kmol})$ & $2,827.80$ & $45,786.04$ & $14,422.21$ \\
\hline \multirow{2}{*}{ Reactants } & $\mathrm{C}_{6} \mathrm{H}_{10} \mathrm{O}_{5}+$ & $4\left(\mathrm{C}_{102} \mathrm{H}_{151} \mathrm{O}_{78}\right)+$ & $4\left(\mathrm{C}_{40} \mathrm{H}_{41} \mathrm{O}_{10}\right)+$ \\
& $+6\left(\mathrm{O}_{2}+3,76 \mathrm{~N}_{2}\right)$ & $+403\left(\mathrm{O}_{2}+3,76 \mathrm{~N}_{2}\right)$ & $+181\left(\mathrm{O}_{2}+3,76 \mathrm{~N}_{2}\right)$ \\
\hline \multirow{2}{*}{ Products } & $6 \mathrm{CO}_{2}+5 \mathrm{H}_{2} \mathrm{O}+$ & $408 \mathrm{CO}_{2}+302 \mathrm{H}_{2} \mathrm{O}+$ & $160 \mathrm{CO}_{2}+82 \mathrm{H}_{2} \mathrm{O}+$ \\
& $+(6 \times 3,76) \mathrm{N}_{2}$ & $+(403 \times 3,76) \mathrm{N}_{2}$ & $+(181 \times 3,76) \mathrm{N}_{2}$ \\
\hline
\end{tabular}




$$
\begin{gathered}
0,234 \times 282.7807+0,012245 \times 786.039+0,044 \times 14.422 .218= \\
=4,404 \times\left[37,31 \times\left(\mathrm{T}_{2}-\mathrm{T}_{\mathrm{ref}}\right)-393.520\right]+2,992 \times\left[38 \times\left(\mathrm{T}_{2}-\mathrm{T}_{\mathrm{ref}}\right)-241.820\right]+ \\
+17,39 \times\left[28,9 \times\left(\mathrm{T}_{2}-\mathrm{T}_{\mathrm{ref}}\right)-0\right] \\
\left(\mathrm{T}_{2}-\mathrm{T}_{\mathrm{ref}}\right)=683,23^{\circ} \mathrm{C} \Rightarrow \mathrm{T}_{2}=708,23^{\circ} \mathrm{C}
\end{gathered}
$$

being $T_{2}$ the flame temperature.

Assuming that biomass falls to $25^{\circ} \mathrm{C}$, and considering that temperature as the reference, you get (Eq 1):

The flame temperature, in real terms is lower because it takes too much oxygen, non burned products appear, fuel has moisture, and so on. This determines the type of installation to use as, for example, you can not use gas turbines, as their yields were acceptable to require flame temperatures higher, the order of $1,150^{\circ} \mathrm{C}$.

If you try to use forest biomass to produce electricity at a conventional steam turbine, the maximum temperature could reach the water vapor in a boiler would not exceed $550^{\circ} \mathrm{C}$, which limits the performance of the core values close $30 \%$.

As you can see, there are two variables associated with the process of burning of forest biomass, one of them is the humidity and the other with excess air to burn fuel to produce complete combustion.

Moisture is the intrinsic value to biomass is closely linked to the flame temperature, ie higher humidity lower flame temperature.

This suggests that the biomass must be stored in drying with the aim of reducing moisture to some values whose maximum temperature flame will enable us to generate steam partner.

As is known, the excess air in the combustion of a sample also includes the maximum flame temperature, ie greater excess air higher qualification, the lower flame temperature.

From a practical viewpoint, it is impossible to burn with an acceptable degree burning, forest biomass with excess air less than $20 \%$.

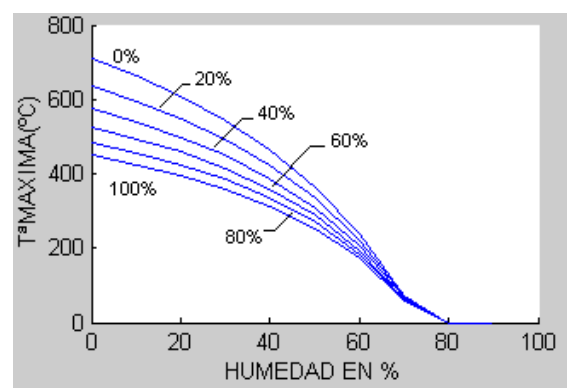

Figure 5. Flame temperature depending on the moisture of the sample
Therefore, the authors have developed a software code that matlab depending on the degree of excess moisture and air to burn shows to give us the maximum flame temperature for a given chemical composition.

This program offers the possibility of drawing twodimensional or three-dimensional graphics to see how they interact with each other above parameters.

\section{Results}

For the operation of the simulation software should be defined input parameters, such as reference temperature, humidity, altitude of the floor above sea level, composition of fuel. The results shown were obtained with values of reference temperature: $25^{\circ} \mathrm{C}$, relative humidity $50 \%$, elevation: $120 \mathrm{~m}$, and composition: $32 \%$ of cellulose, hemicellulose $38 \%$ and $30 \%$ of lignin.

In Figure 5 shows the temperature flame depending on the fuel moisture, this has been represented for several levels of excess air. It is noted that higher humidity to $40 \%$ of calls reached the temperature is very low, and its potential energy of dubious application.

In Figure 6 shows the temperature of the flame depending on the excess air combustion, for different levels of moisture in the fuel. Note the little influence of the excess air.

In Figure 7 presents the interaction of the three dimensions of the fuel moisture and the excess air to the flame temperature. It is seen as the fuel moisture is limiting the excess air in the combustion.

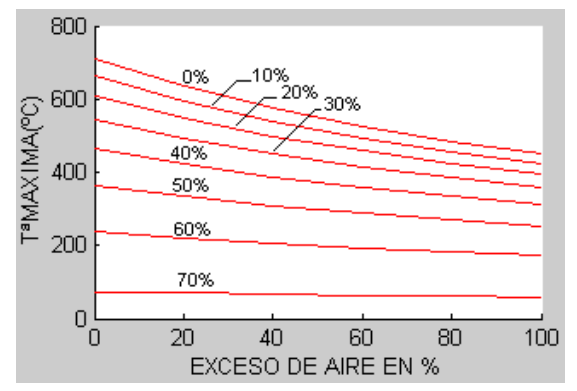

Figure 6. Flame temperature as a function of excess air used 


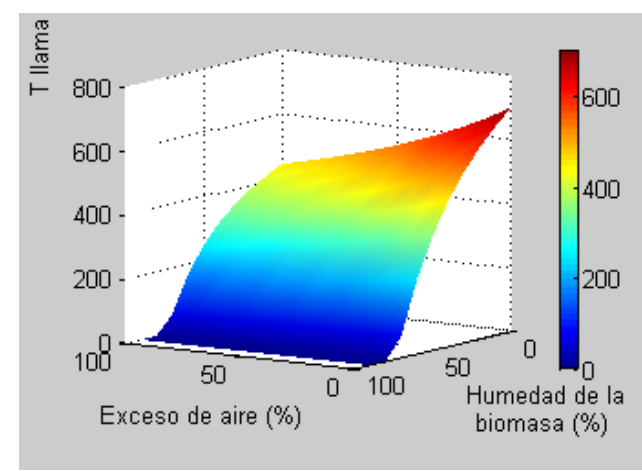

Figure 7. Flame temperature as a function of excess air and moisture of biomass

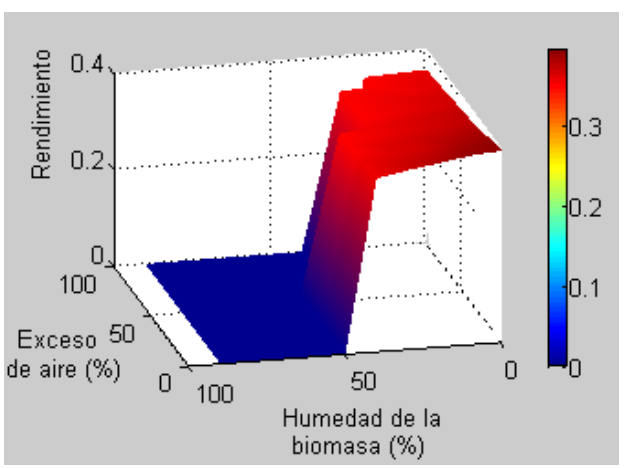

Figure 8. Electrical performance in terms of excess air and moisture of biomass

Table 4. Matrix temperature flame

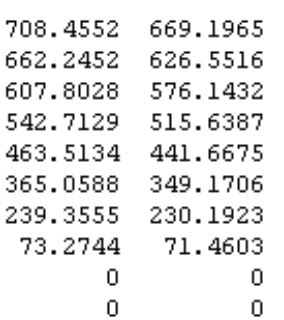

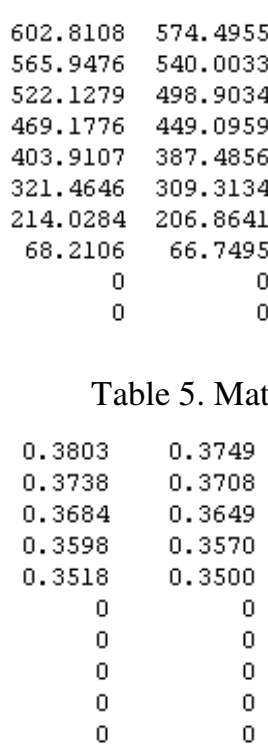

$\begin{array}{rrr}0.3968 & 0.3921 & 0.3666 \\ 0.3914 & 0.3851 & 0.3767 \\ 0.3813 & 0.3752 & 0.3717 \\ 0.3711 & 0.3674 & 0.3638 \\ 0.3590 & 0.3560 & 0.3540 \\ 0.3474 & 0 & 0 \\ 0 & 0 & 0 \\ 0 & 0 & 0 \\ 0 & 0 & 0 \\ 0 & 0 & 0\end{array}$

The results are shown in Table 4, the columns show the variation of excess air, while the rows represent the variation of excess air.

In Figure 8 shows three dimensions of performance power generation in terms of excess air and moisture from the biomass. This has led to a Rankine cycle, assuming an ideal behavior of the pump and the turbine isoentrópico yield of $85 \%$. It can be seen with large wetlands of biomass power generation performance is too low to be considered as a viable solution.

The results are shown in Table 5, the columns show the variation of excess air, while the rows represent the variation of excess air. These results are significantly higher than those in real power, (25$30 \%$ ), due to the irreversibilities of the teams.

\section{Conclusions}

In this paper has made a study of the energy potential of the use of waste wood EG in Cantabria.

$\begin{array}{rrrrrr}548.8246 & 525.4440 & 504.0605 & 484.4266 & 466.3415 & 449.6238 \\ 516.4327 & 494.9241 & 475.2184 & 457.0979 & 440.3769 & 424.9047 \\ 477.7510 & 456.4051 & 440.6439 & 424.2602 & 409.1555 & 395.1340 \\ 430.7505 & 413.9255 & 396.4395 & 364.1367 & 370.6920 & 356.5671 \\ 372.4244 & 356.5640 & 345.7663 & 333.9136 & 322.9049 & 312.6532 \\ 298.1183 & 287.7706 & 278.1777 & 269.2598 & 260.9482 & 253.1830 \\ 200.2223 & 194.0479 & 188.2932 & 182.9168 & 177.8626 & 173.1589 \\ 65.3835 & 64.1034 & 62.9015 & 61.7708 & 60.7052 & 59.6992 \\ 0 & 0 & 0 & 0 & 0 & 0 \\ 0 & 0 & 0 & 0 & 0 & 0\end{array}$

